\title{
Experimental Study of Shielding Material as a Lead in a Nuclear Reactor.
}

\author{
Gehlot Dilip ${ }^{1}$, Gupta Ashok kumar ${ }^{2}$, Deore Rahul ${ }^{3}$. \\ ${ }^{I}$ Mech. Dept., RGPV University,india. \\ ${ }^{2}$ Mech. Dept., RGPV University, india. \\ ${ }^{3}$ Mech. Dept., RGPV University, india.
}

\begin{abstract}
In this paper work study the safety of nuclear reactor pressure vessel as a safety used lead shield to provide adequate safety, avoid radiation. When we supply as lead shield material compare to the other shielding material like concrete block, steel plate, bismuth, glass etc. Lead avoid minimum lowest radiation from nuclear fuel fission process also as point of economical which is best suitable as compare with the gold, Silver etc. Overall $i$ work on lead material details property, as shield its importance to avoid accident in nuclear power plant. Because nuclear radioactive element like uranium is create nature as well as human problem so safety important that point of view we study and experimentally check lead shield property.
\end{abstract}

Keywords: Lead plate, nuclear reactor, radiation, safety material, shielding material.

\section{Introduction}

Every surface emits energy in all possible direction this way of flow of energy in the form of electromagnetic emission is known as radiation .in order to reduce the heat transfer by the radiation between two surface a third surface is introduced in-between them. This surface is known as 'radiation shield '. In the 1950s attention turned to harnessing the power of the atom in a controlled way, as demonstrated at Chicago in 1942 and subsequently for military research, and applying the steady heat yield to generate electricity. This naturally gave rise to concerns about accidents and their possible effects. However, with nuclear power safety depends on much the same factors as in any comparable industry: intelligent planning, proper design with conservative margins and back-up systems, high-quality components and a well-developed safety culture in operations. A particular nuclear scenario was loss of cooling which resulted in melting of the nuclear reactor core, and this motivated studies on both the physical and chemical possibilities as well as the biological effects of any dispersed radioactivity. Those responsible for nuclear power technology in the West devoted extraordinary effort to ensuring that a meltdown of the reactor core would not take place, since it was assumed that a meltdown of the core would create a major public hazard, and if uncontained, a tragic accident with likely multiple fatalities. In avoiding such accidents the industry has been very successful. In over 14,500 cumulative reactor-years of commercial operation in 32 countries, there have been only three major accidents to nuclear power plants - Three Mile Island, Chernobyl, and Fukushima - the second being of little relevance to reactor design outside the old Soviet bloc. The decades-long test and analysis program showed that less radioactivity escapes from molten fuel than initially assumed, and that most of this radioactive material is not readily mobilized beyond the immediate internal structure. Thus, even if the containment structure that surrounds all modern nuclear plants were ruptured, as it has been with at least one of the Fukushima reactors, it is still very effective in preventing escape of most radioactivities. It is the laws of physics and the properties Lead shielding refers to the use of lead as form of radiation protection.

\section{Literature Review}

1.Gamma Ray Attenuation Properties if common shielding material by Daniel R.McAlister-In areas where people are likely to encounter ionizing radiation, it is often necessary to provide shielding to reduce exposure to gamma radiation. Common forms of shielding include rigid materials with limited portability, such as high density concrete, lead bricks, steel plates and cooling pools filled with water. In addition to these classic, well characterized shielding materials, composite materials are becoming increasingly available from shielding manufacturers. These composite materials range from simple advances, such as lead wool blankets with protective plastic covers, to more advanced materials, such as custom moulded components constructed from high density metals dispersed in organic polymers. When evaluating the merits of these composite materials relative to the more classic forms of shielding, it is important to understand the basic principles that lead to gamma ray attenuation. 


\begin{abstract}
2.Development Of Bao:B2o3:Flyash Glass System For Gamma-Rays Shielding Materials Suparat Tuscharoen1, Jakrapong Kaewkhao, Pichet Limsuwan1 And Weerapong Chewpraditkul-Radiations that are most important in nuclear reactor shielding are neutrons, primary gamma-rays originating within the core and the secondary gamma-rays produced by neutron interactions with materials external to the reactor core such as reflector, pressure vessel and shield, etc. Concrete is the most commonly used shield material as it is inexpensive and adaptable for any construction design. There are however several drawbacks associated with the usage of concrete, such as considerable variability in its composition and water content. This variation results in uncertainty in predictions of the radiation distribution and attenuation in the shield. A large water contents leads to decrease of both the density and structural strength of concrete, and the water is lost when concrete becomes hot by absorption of energy from radiations. Some special concretes of higher density than normal have been designed, consisting of elements like barium and iron in addition to light elements. Another drawback of concretes is that they are opaque to visible light and thus it is difficult to see through the concretebased shields. Therefore, it is an important task to develop better radiation shielding materials in terms of size requirements and transparency to visible light. Glass materials are one of the possible alternatives to concrete because they can be transparent to visible light and their properties can be modified by composition and preparation techniques. In nuclear industries, borosilicate glass is one of important glasses because it is mainly used as a medium for immobilizing the radioactive ions present in the waste generated in nuclear reactors.
\end{abstract}

3. Shielding Design to Obtain Compact Marine Reactor Akio YAMAJI and Kiyoshi SAKO Tokai Research Establishment, Japan Atomic Energy Research Institute -To satisfy this condition, an iron shield is installed between the core and steam generator, since only neutrons with an energy above $10 \mathrm{MeV}$ can produce the above mentioned reactions, and iron has an excellent shielding ability against these high energy neutrons. This iron shield also has a role, to decrease the g-ray flux of the diagonally upward direction to reduce the generation of radioactive corrosion products in the secondary water in the steam generator and to maintain the dose rate equivalent around the secondary loop in the engine and reactor rooms within a permissible level. The containment vessel is filled with water in which the cast steel shield is arranged. The outer diameter and height of the containment vessel are 7 and $13.3 \mathrm{~m}$, respectively. The pressure vessel is immersed in water in the containment vessel. The position of the cast steel installed in water of the containment vessel was deter- mined so as to effectively reduce secondary r-rays, to minimize shield weight and keep sufficient working space in the containment vessel.

4. . Nuclear Energy Science Technology, and Applications: Tsetkov, Pavel; Usman, Shoaib , Krivit, Steven, ed Hoboken, NJ: Wiley.-Using lead as the liquid metal provides excellent radiation shielding, and allows for operation at very high temperatures. Also, lead is (mostly) transparent to neutrons, so fewer neutrons are lost in the coolant, and the coolant does not become radioactive. Unlike sodium, lead is mostly inert, so there is less risk of explosion or accident, but such large quantities of lead may be problematic from toxicology and disposal points of view. Often a reactor of this type would use a lead-bismuth eutectic mixture. In this case, the bismuth would present some minor radiation problems, as it is not quite as transparent to neutrons, and can be transmuted to a radioactive isotope more readily than lead. The Russian Alfa class submarine uses a leadbismuth-cooled fast reactor as its main power plant.

\title{
III. History Of Lead-
}

The history of lead use is quite extensive. Objects made of the lead have been evacuated and dated around 6500 B.C. during the Roman Empire, lead production was at 80000 tons per year. In the industrial age of the 1800's, the use of lead further increased. It was used for a variety of things including: utensils, food storage container lining, pottery glaze, water and sewer pipes, ink and paint. Much of its usefulness is due to its plasticity and softness. Lead in the ambient air exists primarily as lead vapours, very fine lead particles and organic halogens such as lead bromide and lead chloride. The most common sources in the atmosphere are gasoline additives, nonferrous smelting plants and battery and ammonization manufacturing in 1985, motor vehicle emissions accounted for $81 \%$ of lead emissions nationwide. Today, transportation is responsible for less than $30 \%$. The national strategy for controlling lead has been to decrease the lead content in the gasoline as of December 31, 1995; lead was banned from use in gasoline. Lead emissions from stationary sources have been substantially reduced by control programs oriented toward attainment of the particulate matter and lead ambient standard. Lead is unique among the toxic heavy metals in that it is relatively abundant in the earth crust. Natural sources of atmospheric lead include soil erosion by wind, volcanic dust, forest fires, sea salt, and decay of radon gas. However the greatest risk of exposure is from man- made processes and products centuries of mining, smelting and the use of large quantity of lead have resulted in extensive environmental contamination. Lead is present in the food, water, air, soil. Paint and other materials with which the general population comes in contact. Each is potential path for the human lead exposure via inhalation or ingestion. 


\subsection{Theory of lead -}

\section{Selection Of Materials-}

It has face centre cubic structure and has good ductility, malleability. It is very soft (-4 Brennel hardness number) and has low melting point $\left(327^{\circ} \mathrm{C}\right)$ with high density $\left(11.34 \mathrm{gm} / \mathrm{cm}^{3}\right)$. It has low electrical conductivity, high coefficient of thermal expansion, high corrosion resistance and good lubricating property. Its recrystallization temperature is below room temperature. Its X-ray and gamma-ray absorbing power is high . it get alloyed with other low melting element such as tin , antimony, arsenic etc. and is completely insoluble in brasses, bronze and steels .It is widely used for manufacture of storage batteries and tetraethyl lead as the ant knocking ingredient in high grade petrol it is used for shielding against X -ray and gamma ray some of the other uses lead include coating on steel wires because of its good lubricating property which assist in wire drawing, equipment in chemical industry because of its high corrosion resistance, as a joining material for cast iron pipes because of its low melting point, low cost, small addition of brasses, bronzes and steel which improve mach inability and for manufacture of alloy such as Babbitt's, solders, type metal etc.Lead of purity $99.99 \%$ and the material to hold the Lead membrane unit is Aluminium. Lead is mainly selected due to its softness, high density, good sensitivity for pressure and temperature and also, unlike other metals its thickness can be fabricated to thickness suitable for bursting at the predetermined pressure. Aluminium is also selected for its softness and thermal conductivity. to hold the safety membrane devices i.e. the Lead membrane, metal like Aluminium is well suited. It's very soft, has low melting point $\left(327^{0} 0\right)$ with high density $\left(11.34 \mathrm{gm} / \mathrm{cm}^{3}\right)$. It has low electric conductivity, high coefficient of thermal expansion, high corrosion resistance and good lubricating property and it has used shielding against $\mathrm{X}$-rays and gamma rays.

\begin{tabular}{|l|l|l|}
\hline Material & Having thickness $(\mathbf{c m})$ & Density $\left(\mathbf{g} / \mathbf{c m}^{\mathbf{3}}\right)$ \\
\hline Lead & $0.4-1$ & 11.3 \\
\hline Concrete & $2.4-6.1$ & 3.33 \\
\hline Steel & $0.99-2.5$ & 7.86 \\
\hline Wood & $11-29$ & 0.56 \\
\hline
\end{tabular}

Table 1-Comparisons lead density with other material.

\subsection{Theory Shielding Material -}

The reactor is a source of intense radioactivity as mentioned earlier and these radiations are very harmful to the human life. the common radiation from the reactor are $\alpha$-rays , $\beta$-rays and fast neutron . to prevent effect of these radiation on the human life is necessary to absorb them before emitting to the atmosphere .neutron, gamma ray and all other radiation are effectively absorb by the concrete and steel. The inner lining of the core is made up of 50 to $60 \mathrm{~cm}$ thick steel plate and it is further thickened by few metres using concrete. the lining of steel plate absorb these energies and becomes heated but prevent the adjacent wall of reactor vessel from beginning heated. The thermal shield (steel plate) is cooled by the circulation of water.

The intensity of radiation and radioactive fragment from the reactor core is too high for the human body to tolerate. Therefore, it is necessary to surround the reactor with shielding material to prevent damage of human body due to radiation. Shielding material The radiation from nuclear reactor is extremely varied in character and its ability to penetrate. The common nuclear radiation is gamma ray, neutron, X-ray, $\alpha$ - ray and $\beta$ - radiation. The and $\beta$ - radiation are absorb in smaller thickness of the shielding. Gamma radiation which penetrates much due to their high energy level and frequency require higher thickness of the shielding material. Neutrons have high power of penetration and do not follow any defined path through the shield material. During slowing down the neutrons or absorption due to the collision with the nuclei of the other materials, some materials also emits secondary gamma radiation. The shield should be design only to reduce or absorb gamma and neutron radiation. The magnitude of nuclear radiation is extremely high and if it is not prevented, it will have very bad effect on the human life and biological plant . the radiation of $60 \mathrm{MW}$ plant was estimated to be equivalent to 1000 tons of radium.

\subsection{Desirable shield material property-}

1.It must have a high efficiency for absorbing gamma radiation with minimum thickness of shielding material .

2. Density of material must remain constant during operation . it should not have local cavity and crack through which radiation may leak . the material must have uniform density .

3. it must have high density to attenuate the gamma radiation and it must contain light material (hydrogen or water ) to attenuate neutron .

4. it should not be decompose or weaken under influence of radiation .

5. it must be fire resistant . 


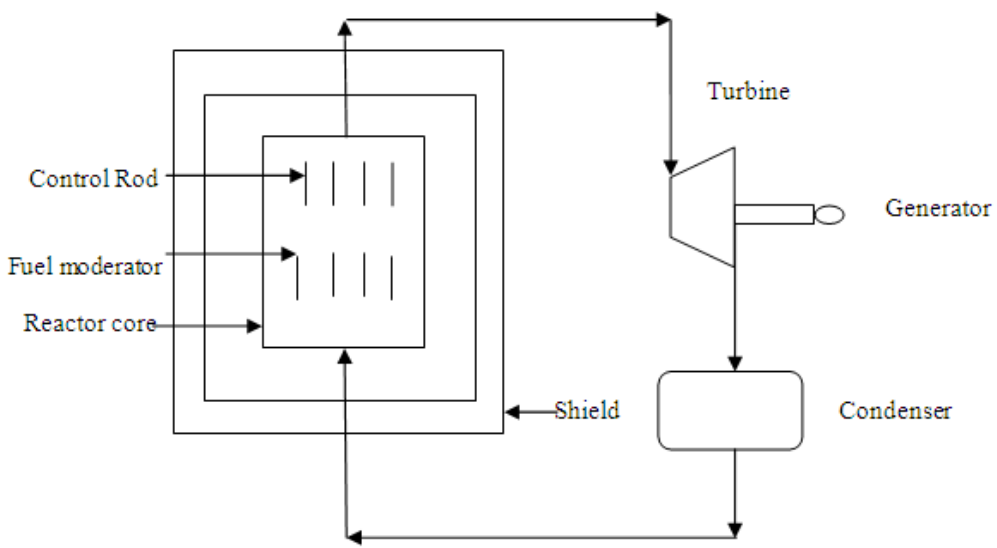

Fig. 1- Location Of Shield In Nuclear Reactor Pressure Vessel.

\subsection{Property of other materials which are used as shielding materials -}

Concrete- concrete is one of the cheapest and most effective shielding material because it contains heavy as well as light material $\left(\mathrm{H}_{2} \mathrm{O}\right)$ which are essential to attenuate gamma radiation and neutrons respectively . the density of concrete varies with the ingredient used the commonly used concrete has a density of $2400 \mathrm{~kg} / \mathrm{m}^{3}$ and contain $5-10 \%$ water and it is also satisfactory shielding material . the shielding property of heavy materials (sand, gravel and cement ) against gamma radiation and light substance $\left(\mathrm{H}_{2} \mathrm{O}\right)$ against neutron radiation are combined together in the concrete . some of the sand and gravel aggregate is replaced by minerals (barium sulphate ) if increased concentration of heavy materials is desired . Presently variety of concrete are develop with density of $6000 \mathrm{~kg} / \mathrm{m}^{3}$.The addition of boron compound in concrete during preparation is recommended by American designers. The addition of boron in concrete help to arrest thermal neutrons and secondary radiation almost instantaneously. the absorption in radiation generate large amount of heat and concrete has relatively low ability with stand with high temperature gradient. The strengthening of the concrete is necessary as high thermal stress is develop due to the large thermal gradient and this is a generally done by reinforcement. Rockwell suggest that the critical temperature of the concrete is $65.6^{\circ} \mathrm{C}$. because with an increase in temperature, e.g. concrete losses more than $50 \%$ of bound water at $100^{\circ} \mathrm{C}$. therefore mean must be provided to protect the concrete the dying out the bound water play very important part as a shielding material to attenuate the neutrons . the most of the heat librated lies in the first $10 \%$ of the shield thickness as radiation absorption decreases exponentially with distance . the temperature gradient in the concrete can be reduce greatly by placing a thin iron shielding between the core and biological concrete shield . iron used as a thermal shield because high mass number material is most effective in absorbing gamma radiation and causing inelastic scattering of fast neutron. Generally two neutron from the iron alloy, each $10 \mathrm{~cm}$ thick providing $10 \mathrm{~cm}$ passage between them for air cooling, generally used as a thermal shielding $96 \%$ of heat generated is taken by thermal shield and remaining $4 \%$ is passed through the concrete shield of $3 \mathrm{M}$. thick.

\section{Fabrication Of Lead Plate:-}

1. Lead sheet of dimension $140 \times 140 \mathrm{~mm}$ is cut from the lead sheet of thickness $1.6 \mathrm{~mm}$.

2. Cut the Lead membrane by using cutting fixture of cutting edge diameter $129 \mathrm{~mm}$, cutting fixture includes cutting punch and screw jack setup.

3. After above operation the lead disc will be having the diameter of $129 \mathrm{~mm}$ and thickness of $1.6 \mathrm{~mm}$.

4. A rolling fixture of $4 \mathrm{~kg}$ weight and $20 \mathrm{~kg}$ on each side of the roller (uniformly distributed) is rolled over the lead disc to reduce thickness between $1.20-1.25 \mathrm{~mm}$.

5. After rolling, the diameter of lead disc is again increased due to material flow.

6. Sizing and grooving fixture of diameter $117.8 \mathrm{~mm}$ and grooving diameter of $99.6 \mathrm{~mm}$ is used to obtain the final dimension on the lead disc.

7. The final required dimension of lead membrane is diameter $117.8 \mathrm{~mm}$ and thickness $1.20-1.22 \mathrm{~mm}$ is obtained.

8. Grooving depth is $0.55 \mathrm{~mm}$ from the surface of the lead disc.

9. Checked dimensions at multiple places of the surface, minimum 8 places, using Micrometer.

10. After checking all the dimensions, the lead disc is connected with aluminium flanges and it is tightened with torque wrench for set torque $5 \mathrm{Nm}$. 
6.1.Metallurgical Result-

\section{Test Result}

Lead plate thickness- $1.5 \mathrm{~mm}$ thick

\begin{tabular}{|l|l|l|l|l|}
\hline $\begin{array}{l}\text { Our lab No. } \\
\text { Wet Chemical Method }\end{array}$ & $\begin{array}{l}\text { Test no.AK/10231-1 } \\
\text { LS-1A content find in } \\
\text { term of } \%\end{array}$ & $\begin{array}{l}\text { Test no. AK/10231-2 } \\
\text { LS-1B content find in } \\
\text { term of } \%\end{array}$ & Test method & $\begin{array}{l}\text { Ideal requirement } \\
\text { content in term \% }\end{array}$ \\
\hline \% COPPER & 0.0040 & 0.00041 & & $(0.004-0.080)$ \\
\hline TIN & $<0.001$ & $<0.001$ & & $(0.002 \mathrm{MAX})$. \\
\hline \% ZINC & $<0.001$ & $<0.001$ & & $(0.001 \mathrm{MAX})$. \\
\hline \% LEAD & 99.51 & 99.51 & MS/QS/17: 2011 & $(99.9 \mathrm{MIN})$. \\
\hline \% IRON & 0.002 & 0.002 & & $(0.002 \mathrm{MAX})$. \\
\hline \% ARSIMONY & 0.0017 & 0.0018 & MS/QS/17: 2011 & $(0.002 \mathrm{MAX})$. \\
\hline \% BISMUTH & 0.009 & 0.009 & MS/QS/17:2011 & $(0.005 \mathrm{MAX})$. \\
\hline \% SILVER & 0.015 & 0.015 & MS/QS/17:2011 & $(0.002-0.020)$ \\
\hline
\end{tabular}

Table 2- Different Metallurgical Test of Lead Sample

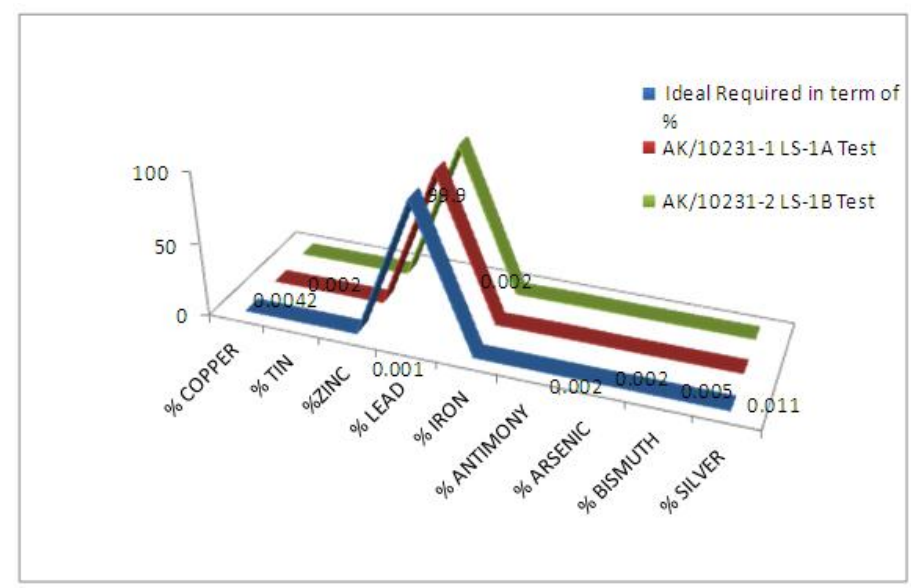

Graph1-Comparison metallurgical test contain present in sample lead material .

Discussion- graph and table of lead material metallurgical test AK/10231-1 LS-1A \& AK/10231-1 LS1B two test method which gives actual lead and other content present in a sample lead material should be purity $99 \%$ required in both test we get $99 \%$ lead content in term of \% and other content which is minor, if material purity more which gives accurate reading for shielding as lead material importance of test to get exact and accurate testing of lead material.

\section{2.-Ultimate tensile test-}

\begin{tabular}{|c|c|c|c|}
\hline \multicolumn{2}{|l|}{ Input Data } & \multicolumn{2}{|l|}{ Output Data } \\
\hline Specimen Shape & Flat & Load At Yield & $4.5 \mathrm{kN}$ \\
\hline Specimen Type & Lead & Elongation At Yield & $27.800 \mathrm{~mm}$ \\
\hline Specimen Description & $100 * 1.12 \mathrm{~mm}$ & Yield Stress & $138.547 \mathrm{~N} / \mathrm{mm}^{2}$ \\
\hline Specimen Width & $29 \mathrm{~mm}$ & Load at Peak & $5.460 \mathrm{kN}$ \\
\hline Specimen Thickness & $1.12 \mathrm{~mm}$ & Elongation at Peak & $2.300 \mathrm{~mm}$ \\
\hline Initial Distance Between Grips & $14 \mathrm{~mm}$ & Tensile Strength & $168.103 \mathrm{~N} / \mathrm{mm}^{2}$ \\
\hline Pre Load Value & $\mathbf{0 K n}$ & Load At Break & $4.500 \mathrm{kN}$ \\
\hline Max. Load & $400 \mathrm{Kn}$ & Elongation At Break & $27.800 \mathrm{~mm}$ \\
\hline Max. Elongation & $200 \mathrm{~mm}$ & Breaking Strength & $138.54 \mathrm{~N} / \mathrm{mm}^{2}$ \\
\hline Specimen Cross Section Area & $32.48 \mathrm{~mm}^{2}$ & $\%$ Reduction Area & $19.95 \%$ \\
\hline Final Specimen Width & $26 \mathrm{~mm}$ & $\%$ Elongation & $216 \%$ \\
\hline Final Specimen Thickness & $1 \mathrm{~mm}$ & & \\
\hline Final Gauge Length & $44.24 \mathrm{~mm}$ & & \\
\hline Final Area & $26 \mathrm{~mm}^{2}$ & & \\
\hline
\end{tabular}

Table 3- Ultimate Tensile Test Data of Sample Lead Material. 


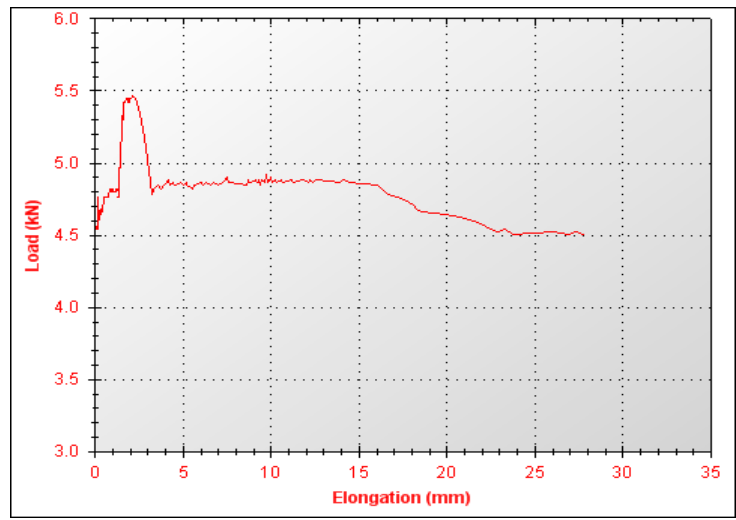

Graph 2- Elongation (mm) Vs Load (KN) of sample lead material on UTM

Discussion-as lead testing in ultimate tensile test apply load from 4.5 KN upto $5.4 \mathrm{KN}$.it shows less elongation afterward decrease load. From 4 to $15 \mathrm{~mm}$ elongation shows constant load after $15 \mathrm{~mm}$ its load decreases with respect to elongation at $27 \mathrm{~mm}$ elongation lead material break at load applied 4.5. KN.

Due to the more elongation of lead which is ductile material and high malleability has a high thermal coefficient at very less range of 4.5-5.4.KN (force) load it more elongated shows that lead material is a high sensitive with respect to pressure $(\mathrm{P}=\mathrm{F} / \mathrm{A})$ and temperature(because pressure is directly proportional to the temperature ) which easily sense the temperature and pressure condition so changes in term more elongation low melting $\left(324{ }^{0} \mathrm{C}\right)$ temperature which is desired condition of shielding material.

\section{Conclusion-}

Nuclear safety covers the actions taken to prevent nuclear and radiation accidents or to limit their consequences. The nuclear power industry has improved the safety and performance of reactors, and has proposed new safer (but generally untested) reactor designs but there is no guarantee that the reactors will be designed, built and operated correctly. Mistakes do occur and the designers of reactors at Fukushima in Japan did not anticipate that a tsunami generated by an earthquake would disable the backup systems that were supposed to stabilize the reactor after the earthquake. According to UBS AG, the Fukushima I nuclear accidents have cast doubt on whether even an advanced economy like Japan can master nuclear safety. Above discussion shows the proper safety in nuclear reactor for avoids radiation leakages so properly shielding as a lead material very important to avoid accident in power plant. in my paper i work on shielding material lead as safety for nuclear power plant .also in India there is very less \% of work in nuclear energy, wide scope to install nuclear power plant in India. To become develop country .the adoption of nuclear energy for the generation of power is inventible to the nations where other sources of generation are inadequate and scare like in western Europe the U.K. is an outstanding example of this where presently the major sources of power generation in nuclear energy. The propose of this article is not to discuss the importance of the nuclear power for a particular country but to find out the economical, safety adoption of nuclear power.

\section{Journal papers:}

\section{References}

[1]. Danielr.Mcalister, Ph.D. Pg Research Foundation, ' Gamma Ray Attenuation Properties of Common Shielding Materials'.

[2]. Pichet Limsuwan And Weerapong Chewpraditkul, 'Development of Bao:B2O3:Flyash glass system for gamma-rays shielding materials'.

[3]. Akio Yamaji And Kiyoshi Sako Tokai Research Establishment, 'Shielding design to obtain compact marine reactor' (Mar 2012)

[4]. Krivit, Steven, ed Hoboken, NJ: Wiley Nuclear Energy: Science, Technology, and Applications.Tsetkov, Pavel; Usman, Shoaib (2011).

[5]. Samir Yousha El-Kameesy1, Sahar Abd El- Yaser Abd Allah , 'Shielding Properties of Lead Zinc Borate Glasses'.

[6]. Schlattl H, Zankl M, Eder H, Hoeschen C. 'Shielding properties of lead-free protective clothing and their impact on radiation doses.'

[7]. Vienna International Atomic Energy Agency, (1999).

[8]. Helmute W.Lange MD. , Heinervon Boetticher Breman , Germany "reduction of operator radiation dose by a pelvic lead shield during cardiac catheterization by radial access".

[9]. A.K.Dureja , S.K.Sinha ,R.K.Sinha Reactor Design And Development Group BARC ,Trombay , Bombay , India. “analysis of intraction of calandria tubes with the end shield in advanced heavy water reactor (AHER)".

[10]. Eliza Stickland, 'What went wrong in japans nuclear reactors'. (16 mar 2011).

\section{Books:}

[11]. J.P.Holman,heat transfer, VII edition, TATA mcgraw hill publication.

[12]. Domkundwar and Arora "Power Plant Engineering", Dhanpat Rai and Sons, New Delhi

[13]. V.D.KODGIRE, S.V.KODGIRE, "Material Science And Metallurgy", Everest publication House , 2010 Edition .

[14]. Dr. R.YADAV, "Steam \& gas turbine and power plant engineering", Central publication house, 2012 Edition , page no. $925-959$. 